\title{
Article \\ Effects of COVID-19 Lockdown on Weight, Body Composition, and Behavior of Children, Adolescents, and Young Adults with Prader-Willi Syndrome
}

\author{
Andrea Karoline Mohr ${ }^{1, *} \mathbb{B}$, Constanze Laemmer ${ }^{2}$, Sandra Schulte ${ }^{1}$ and Bettina Gohlke ${ }^{1}$ \\ 1 Department of Pediatric Endocrinology and Diabetology, Children's Hospital, University of Bonn, \\ Venusberg-Campus, 53127 Bonn, Germany; sandra.schulte@ukbonn.de (S.S.); \\ bettina.gohlke@ukbonn.de (B.G.) \\ 2 Pediatric Endocrinology and Diabetology, St. Bernward Hospital, Treibestraße 9, 31134 Hildesheim, Germany; \\ dr.c.laemmer@bernward-khs.de \\ * Correspondence: andrea.k.mohr@gmx.de
}

Citation: Mohr, A.K.; Laemmer, C.; Schulte, S.; Gohlke, B. Effects of COVID-19 Lockdown on Weight, Body Composition, and Behavior of Children, Adolescents, and Young Adults with Prader-Willi Syndrome. J. Clin. Med. 2021, 10, 4746. https:// doi.org/10.3390/jcm10204746

Academic Editor: Assumpta Caixàs

Received: 17 September 2021

Accepted: 13 October 2021

Published: 16 October 2021

Publisher's Note: MDPI stays neutral with regard to jurisdictional claims in published maps and institutional affiliations.

Copyright: () 2021 by the authors. Licensee MDPI, Basel, Switzerland. This article is an open access article distributed under the terms and conditions of the Creative Commons Attribution (CC BY) license (https:// creativecommons.org/licenses/by/ $4.0 /)$.

\begin{abstract}
To reduce transmission of the coronavirus disease 2019 (COVID-19), many countries implemented lockdowns, causing the closure of childcare services. This study was designed to evaluate the impact of the COVID-19 lockdown in March-April 2020 on children, adolescents, and young adults with Prader-Willi syndrome (PWS) living in Germany. We recruited 180 participants with a genetically confirmed PWS. All families completed a questionnaire, and participants underwent a post-lockdown assessment; the last examination before the lockdown was determined as the prelockdown assessment. We used bivariate analyses to compare pre- and post-lockdown outcomes.

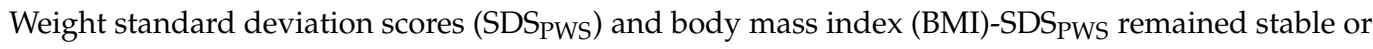
even decreased in some age groups. A statistically significant gain in lean body mass (LBM) was found in all groups $<18$ years of age. We observed an increase in IGF-I and IGFBP-3 concentrations without a significant change in growth hormone (GH) dosage. Most families (95.4\%) reported set mealtimes and implementation of structured activities (72.2\%) during the lockdown period. We therefore suggest that the favorable development of weight/BMI and LBM was caused by an interplay of a suspected enhanced GH administration and continuous parental commitment. However, more intense behavioral problems were observed in $45.7 \%$, which persisted post-lockdown in $33.7 \%$.
\end{abstract}

Keywords: Prader-Willi syndrome; genetic obesity; COVID-19; physical activity; eating behavior; growth hormone

\section{Introduction}

Prader-Willi syndrome (PWS) is a complex multisystem disorder caused by the absence of the expression of paternally inherited imprinting genes on chromosome 15q11q13 caused by a paternal de novo deletion, maternal uniparental disomy (UPD), or an imprinting center defect (ID) [1,2]. Cardinal features of the syndrome include neonatal hypotonia with feeding difficulties and failure to thrive, followed by hyperphagia and food-seeking behavior with onset in early childhood [1,3]. Individuals with PWS show an altered body composition, with increased adiposity and a decreased lean body mass (LBM) as a manifestation of growth hormone (GH) deficiency [4-7]. The reduction in muscle mass causes a reduced resting energy expenditure and avoidance of physical exercise. Together with increased energy intake due to hyperphagia, individuals with PWS show a high prevalence of severe obesity [8,9]. Apart from GH deficiency, common endocrinopathies in individuals with PWS include hypogonadism and hypothyroidism [6,7]. Other characteristic features include developmental delay and behavioral problems [2]. First-line management of PWS includes a low-calorie diet and physical exercise in conjunction with GH therapy, as GH improves body composition and, thus, metabolism [10,11]. Through 
strict management requiring multidisciplinary care, a normal body mass index (BMI) can be achieved $[3,6]$.

At the beginning of 2020, there was a rapid global expansion of the coronavirus disease 2019 (COVID-19); on 11 March 2020, the World Health Organization (WHO) declared a worldwide pandemic [12]. To reduce transmission occurring through respiratory droplets, many countries imposed regulations of social distancing and lockdowns [13]. Children with PWS, who commonly attend special-need childcare services, had to be cared for at home, and therapy sessions were canceled. Therefore, families suddenly had to manage the care for their child with PWS without the support of a multidisciplinary team. This study was designed to assess the impact of the lockdown on children, adolescents, and young adults with PWS in Germany, focusing on changes in anthropometric parameters and body composition, as well as metabolic factors and behavior.

\section{Materials and Methods}

\subsection{Participants}

The participants of this retrospective, longitudinal study were recruited at a single PWS center in Germany. Patients with a genetically confirmed PWS who visited the clinic between 4 May 2020 and 11 September 2020 were asked to participate. The study was approved by the Ethics Committee of the University of Bonn, Germany. All individuals underwent an examination, which was used as the follow-up assessment post-lockdown. The last assessment before the lockdown was determined as the pre-lockdown examination. Of 231 individuals with PWS visiting the clinic in 2020, we collected data of 186; 6 participants were excluded due to missing pre-lockdown examinations, resulting in a final sample of 180 patients ( 95 female). In the final sample, the genetic subtype had not been determined in $41 \% ; 28 \%$ had a UPD, $22 \%$ a deletion, $3 \%$ an ID, and $6 \%$ a non-deletion subtype, which had not been differentiated into UPD or ID. Thirteen children (7\%) had an additional disease (prematurity $<30$ gestational weeks, type I diabetes mellitus, medically treated seizures, Triple $X$ syndrome, spinal malformation). Twenty individuals (11.1\%) took Levothyroxine for the treatment of hypothyroidism during the lockdown. In the group aged $11-17$ years, five boys $(20 \%)$ and two girls $(10 \%)$ received sex steroids; in the young adults, twelve women $(100 \%)$ and nine men $(60 \%)$ took hormone replacement therapy. The participants were primarily Caucasian; ethnic minorities were not represented. Median interval between pre-lockdown and follow-up was 6.25 months in children and nine months in adults. Table 1 shows patients' characteristics.

Table 1. Characteristics of children and adolescents with PWS during the lockdown in March-April 2020.

\begin{tabular}{|c|c|c|c|c|c|}
\hline & $<2$ Years & 2-6 Years & 7-10 Years & 11-17 Years & $\geq 18$ Years \\
\hline Sample size (n) & 10 & 59 & 38 & 46 & 27 \\
\hline Mean age in years (range) & $\begin{array}{c}1.38 \\
(0.94-1.96) \\
\end{array}$ & $\begin{array}{c}4.07 \\
(2.02-6.94) \\
\end{array}$ & $\begin{array}{c}8.92 \\
(7.05-10.95)\end{array}$ & $\begin{array}{c}14.33 \\
(11.26-17.99)\end{array}$ & $\begin{array}{c}23.38 \\
(18.49-33.55)\end{array}$ \\
\hline Females (\%) & $10(100 \%)$ & $31(52.5 \%)$ & $19(50 \%)$ & $23(50 \%)$ & $12(44.4 \%)$ \\
\hline $\begin{array}{l}\text { Median interval between } \\
\text { assessments (months) }\end{array}$ & 5 & 6 & 6.5 & 7 & 9 \\
\hline n GH therapy pre-lockdown (\%) & $5(50 \%)$ & $55(93.2 \%)$ & $37(97.4 \%)$ & $34(73.9 \%)$ & $2(7.4 \%)$ \\
\hline n GH therapy intra-lockdown (\%) & $10(100 \%)$ & $56(94.9 \%)$ & $38(100 \%)$ & $34(73.9 \%)$ & $2(7.4 \%)$ \\
\hline
\end{tabular}

Abbreviation: growth hormone $(\mathrm{GH})$.

\subsection{Anthropometric Parameters and Body Composition}

Height and weight were measured at both assessments. Height was assessed using a rigid stadiometer, and weight was measured to the nearest $0.1 \mathrm{~kg}$ on a mechanical scale. BMI was calculated as weight/height ${ }^{2}$. We calculated standard deviation scores (SDS) according to age and sex for height, weight, and BMI using reference values for children 
with PWS (SDS ${ }_{\text {PWS }}$ [14]. Body composition was determined at both time points using bioelectrical impedance analysis (BIA) (Nutribox, Data Input). BIA is a non-invasive method, which relies on the different electrical properties of biological tissues. The assessment was performed after an overnight fast in a prone position. Patient information (sex, age, height, and weight) was entered, and patients were asked to lie still for five minutes to ensure an even blood distribution. During the analysis, two electrodes generate a weak electrical current inside the body. Total impedance is proportional to the conductor's length and inversely proportional to its cross-sectional area. Muscle mass, containing water and dissolved electrolytes, conducts the electrical current, whereas bone and adipose tissue act as insulators. The software calculates LBM ( $\mathrm{kg}$ ), fat mass ( $\mathrm{kg}$ and percent), and total body water (L) $[15,16]$. Due to a lack of reference values for children aged 0-3 years, children below the age of three were excluded from this analysis.

\subsection{Hormonal Parameters, Lipoproteins and Carbohydrate Metabolism}

IGF-I concentrations were measured by an immunoassay (IMMULITE ${ }^{\circledR} 2000$ systems, Siemens Healthcare Diagnostics Products Ltd., Caernarfon, UK). IGF-I (nanograms per milliliter) was measured after employing excess IGF-II to saturate IGFBPs. The detection limit was $0.02 \mathrm{ng} / \mathrm{mL}$. Interassay variance was 7.4 for IGF-I, and intraassay variance 5.6. Estradiol and testosterone concentrations were measured by chemiluminescent immunoassays using commercially available kits by Siemens Healthcare Diagnostics: Dimension Vista ${ }^{\circledR}$ System Flex ${ }^{\circledR}$ reagent cartridge LOCI ${ }^{\circledR}$ Estradiol (AMR: $11-1500$ pg $/ \mathrm{mL}$ [40-5506 pmol/L]) and IMMULITE ${ }^{\circledR} 2000$ Total Testosterone (calibration Range: 20-1600 ng/dL (0.7-55 nmol/L)). Total cholesterol, triglycerides, high-density lipoprotein (HDL), and low-density lipoprotein (LDL) were measured using the Roche cobas ${ }^{\circledR}$ c502 module. For the assessment of Vitamin D, a competitive immunoassay using the Roche cobas ${ }^{\circledR}$ e601 module was performed. Intra- and interassay coefficients of variation were below $5 \%$ in all methods. Fasting blood glucose was measured via a UV test (hexokinase method with Roche cobas ${ }^{\circledR} \mathrm{c} 502$ module). Fasting insulin levels were determined with a sandwich immunoassay (ADVIA Centaur ${ }^{\circledR}$ XPT immunoassay system, Siemens Healthineers). HbA1c was determined immunochemically through an antibody-based immunoassay (Roche cobas $^{\circledR}$ c502 module).

\subsection{The Questionnaire}

Parents and caregivers of all participants were asked to complete a questionnaire comprising questions of five thematic blocks. The questionnaire can be found in the Supplementary Material (S1). Firstly, responders were asked to describe the living situation, including parental occupation. The second block contained questions about the care and therapies received pre-, intra-, and post-lockdown. Questions of the third block covered the structure of everyday life during home confinement. Block number four contained questions about COVID-19 infections and other illnesses since the pre-lockdown assessment. The questions consisted of dichotomous, multiple-choice, scaling, and open questions. Lastly, parents or caregivers were asked to rate family life and their child's behavior on a Likert scale (from 0: no behavioral problems to 9: severe behavioral problems). Improper answers were revoked and consequently excluded from the analysis. Answers were seen as improper when no or multiple options, instead of one, were chosen. No entire questionnaire was excluded. Questions applicable for all participants were answered by $80.0 \%$ to $99.3 \%$ of participants, five questions were answered by less than $80 \%$ (lowest response rate: $65.6 \%)$.

\subsection{Statistical Analysis}

Statistical analysis was performed with IBM SPSS Statistics (versions 26 and 27). We calculated delta values $(\Delta s)$, indicating differences between points of examination. To calculate $\Delta$, the pre-lockdown data were subtracted from the corresponding post-lockdown data. No significant differences in $\Delta$ were found between female and male pairs, making 
a division into subgroups superfluous. Before testing, each parameter was evaluated for normal distribution. If the assumption of normality did not hold, non-parametric testing was performed. For measurements on ratio scales, paired t-tests or Wilcoxon signed-rank tests were used to compare values pre- and post-lockdown. For measurements on ordinal scales (Likert scales), sign tests were performed to compare pre-, intra-, and post-lockdown differences. For the assessment of associations between two variables, we used Pearson $r$ and Spearman rho correlations. To further analyze determinants of pre- and post-lockdown differences, we performed stepwise multiple linear regression analyses in all participants older than two years of age. The $\Delta$ values were used as dependent variables. Independent variables included in the analysis were: sex, post-lockdown age, genetic subtype, GH dosage ( $\mathrm{mg} / \mathrm{kg}$ ), number of siblings, support by other family members, hometown population, living situation (house/apartment), access to a garden, owning a $\mathrm{dog}$, duration of break of childcare services (weeks), duration of break of physiotherapy (weeks), change in daily routine, presence of set mealtimes, presence of set activities, and behavior during the lockdown. Cohen $\mathrm{f}^{2}$ values were calculated to estimate effect sizes. Significance was defined as $p \leq 0.05$.

\section{Results}

\subsection{Anthropometric Parameters and Body Composition}

All the data are shown in Table 2. Weight-SDS PwS $_{\text {and BMI-SDS }}$ PWS decreased with no changes in fat mass in any age group. A statistically significant gain in LBM was found in all assessed age groups below the age of 18 .

\subsection{Hormonal Parameters, Lipoproteins, and Carbohydrate Metabolism}

The data are shown in Table 3. IGFBP-3 concentrations rose significantly in all children, and IGF-I in all children below the age of 11 . There were no significant changes in $\mathrm{HbA} 1 \mathrm{c}$ concentrations in any group. Testosterone concentrations did not change significantly in boys aged 11-17-years, in those receiving testosterone replacement (prelockdown mean: $0.98 \mathrm{ng} / \mathrm{mL}$ vs. post-lockdown mean: $0.96 \mathrm{ng} / \mathrm{mL}, p=0.893$ ), nor in those not taking testosterone (pre-lockdown mean: $1.43 \mathrm{ng} / \mathrm{mL}$ vs. post-lockdown mean: $1.22 \mathrm{ng} / \mathrm{mL}, p=0.570$ ). Similarly, in the $\geq 18$-year-olds taking testosterone (pre-lockdown mean: $4.35 \mathrm{ng} / \mathrm{mL}$ vs. post-lockdown mean: $4.43 \mathrm{ng} / \mathrm{mL}, p=0.779$ ) and those not taking testosterone (pre-lockdown mean: $2.98 \mathrm{ng} / \mathrm{mL}$ vs. post-lockdown mean: $2.61 \mathrm{ng} / \mathrm{mL}$, $p=0.345$ ), concentrations did not change significantly. In girls aged 11-17 years not receiving estradiol, concentrations increased significantly (pre-lockdown mean: $19.36 \mathrm{pmol} / \mathrm{L}$ vs. post-lockdown: $27.9 \mathrm{pmol} / \mathrm{L}, p=0.032$ ). Only two received estradiol replacement; therefore, no statistical analysis was performed. In the $\geq 18$-year-old females, no statistical analysis was performed as concentrations were measured in three women. 
Table 2. Anthropometric parameters before and after the lockdown in March-April 2020. $p$-values > 0.05 depicted as "NS".

\begin{tabular}{|c|c|c|c|c|c|c|c|c|c|c|c|c|c|c|c|c|}
\hline & & \multicolumn{3}{|c|}{$<2$ Years } & \multicolumn{3}{|c|}{ 2-6 Years } & \multicolumn{3}{|c|}{ 7-10 Years } & \multicolumn{3}{|c|}{ 11-17 Years } & \multicolumn{3}{|c|}{$\geq 18$ Years } \\
\hline & & Mean & SD & $p$ & Mean & SD & $p$ & Mean & SD & $p$ & Mean & SD & $p$ & Mean & SD & $p$ \\
\hline \multirow{2}{*}{ Height (m) } & Pre & 0.67 & 0.08 & \multirow[b]{2}{*}{0.005} & 0.96 & 0.12 & \multirow[b]{2}{*}{$<0.001$} & 1.29 & 0.10 & \multirow[b]{2}{*}{$<0.001$} & 1.55 & 0.12 & \multirow[b]{2}{*}{$<0.001$} & 1.67 & 0.12 & \multirow[b]{2}{*}{ NS } \\
\hline & Post & 0.77 & 0.06 & & 1.00 & 0.12 & & 1.33 & 0.10 & & 1.57 & 0.11 & & 1.67 & 0.11 & \\
\hline Height & Pre & 0.15 & 0.69 & \multirow{2}{*}{0.028} & 0.60 & 0.96 & \multirow[b]{2}{*}{ NS } & 0.61 & 0.60 & \multirow[b]{2}{*}{ NS } & 1.19 & 0.93 & \multirow{2}{*}{$<0.001$} & & & \\
\hline SDSPWS & Post & 0.72 & 0.93 & & 0.57 & 1.01 & & 0.66 & 0.61 & & 1.28 & 0.91 & & & & \\
\hline \multirow{2}{*}{ Weight (kg) } & Pre & 6.93 & 1.17 & \multirow{2}{*}{0.005} & 14.52 & 5.15 & \multirow{2}{*}{$<0.001$} & 30.93 & 9.09 & \multirow{2}{*}{$<0.001$} & 54.92 & 18.00 & \multirow{2}{*}{$<0.001$} & 69.07 & 9.75 & \multirow{2}{*}{ NS } \\
\hline & Post & 9.04 & 1.52 & & 16.32 & 5.91 & & 33.17 & 9.99 & & 57.52 & 19.72 & & 67.87 & 11.92 & \\
\hline Weight & Pre & 0.12 & 0.70 & \multirow{2}{*}{ NS } & -0.73 & 0.79 & \multirow[b]{2}{*}{ NS } & -0.78 & 0.73 & \multirow[b]{2}{*}{0.044} & -0.71 & 0.90 & \multirow[b]{2}{*}{ NS } & & & \\
\hline SDSPWS & Post & -0.15 & 0.83 & & -0.81 & 0.80 & & -0.82 & 0.77 & & -0.75 & 0.94 & & & & \\
\hline \multirow{2}{*}{$\begin{array}{c}\text { BMI } \\
\left(\mathrm{kg} / \mathrm{m}^{2}\right)\end{array}$} & Pre & 15.30 & 1.31 & \multirow{2}{*}{ NS } & 15.51 & 2.09 & \multirow{2}{*}{ NS } & 18.35 & 3.76 & \multirow{2}{*}{ NS } & 22.38 & 5.23 & \multirow{2}{*}{ NS } & 24.75 & 3.07 & \multirow{2}{*}{ NS } \\
\hline & Post & 15.15 & 1.66 & & 15.88 & 2.55 & & 18.45 & 3.68 & & 22.77 & 5.99 & & 24.20 & 3.30 & \\
\hline BMI & Pre & -0.30 & 1.25 & \multirow{2}{*}{0.037} & -1.15 & 0.73 & & -1.24 & 0.67 & & -1.36 & 0.65 & & & & \\
\hline $\mathrm{SDS}_{\mathrm{PWS}}$ & Post & -1.08 & 1.29 & & -1.21 & 0.77 & NS & -1.32 & 0.65 & 0.007 & -1.39 & 0.71 & NS & & & \\
\hline $\mathrm{BM}(\mathrm{kg})$ & Pre & & & & 13.72 & 3.17 & & 21.97 & 4.58 & & 35.58 & 8.89 & & 44.94 & 7.93 & \\
\hline LBM (kg) & Post & & & & 15.11 & 3.49 & $<0.001$ & 23.43 & 5.41 & $<0.001$ & 37.24 & 9.99 & $<0.001$ & 43.26 & 9.56 & NS \\
\hline$(\%)$ & Post & & & & 17.02 & 9.07 & NS & 26.75 & 7.41 & NS & 32.27 & 8.73 & NS & 35.21 & 6.62 & NS \\
\hline
\end{tabular}

Abbreviations: standard deviation scores for children with Prader-Willi syndrome (SDS $\mathrm{PWS}$ ), body mass index (BMI), lean body mass (LBM).

Table 3. IGF-I and IGFBP-3, lipoproteins, and carbohydrate metabolism before and after the lockdown in March-April 2020. $p$-values >0.05 depicted as "NS".

\begin{tabular}{|c|c|c|c|c|c|c|c|c|c|c|c|c|c|c|c|c|}
\hline & & \multicolumn{3}{|c|}{$<2$ Years } & \multicolumn{3}{|c|}{ 2-6 Years } & \multicolumn{3}{|c|}{ 7-10 Years } & \multicolumn{3}{|c|}{ 11-17 Years } & \multicolumn{3}{|c|}{$\geq 18$ Years } \\
\hline & & Mean & SD & $p$ & Mean & SD & $p$ & Mean & SD & $p$ & Mean & SD & $p$ & Mean & SD & $p$ \\
\hline IGF-1 & Pre & 46.97 & 29.42 & \multirow[b]{2}{*}{0.008} & 115.17 & 58.46 & \multirow[b]{2}{*}{$<0.001$} & 233.25 & 74.29 & \multirow[b]{2}{*}{0.022} & 307.19 & 109.17 & \multirow[b]{2}{*}{ NS } & 146.63 & 46.46 & \multirow[b]{2}{*}{ NS } \\
\hline$(\mu \mathrm{g} / \mathrm{L})$ & Post & 81.73 & 41.63 & & 147.61 & 59.31 & & 264.11 & 108.65 & & 319.13 & 118.17 & & 148.63 & 71.97 & \\
\hline IGFBP-3 & Pre & 2.56 & 0.85 & \multirow{2}{*}{0.008} & 4.09 & 1.11 & \multirow{2}{*}{$<0.001$} & 5.51 & 1.00 & \multirow{2}{*}{$<0.001$} & 6.70 & 1.41 & \multirow{2}{*}{0.001} & 5.65 & 1.27 & \multirow{2}{*}{ NS } \\
\hline$(\mathrm{mg} / \mathrm{L})$ & Post & 4.13 & 1.18 & & 5.01 & 1.16 & & 9.01 & 16.39 & & 7.41 & 1.72 & & 5.88 & 1.19 & \\
\hline \multirow{2}{*}{$\begin{array}{l}\text { Total cholesterol } \\
\qquad(\mathrm{mg} / \mathrm{dL})\end{array}$} & Pre & 139.22 & 31.91 & \multirow{2}{*}{ NS } & 163.56 & 28.79 & \multirow{2}{*}{ NS } & 157.92 & 27.14 & \multirow{2}{*}{ NS } & 155.52 & 29.45 & \multirow{2}{*}{ NS } & 158.50 & 37.06 & \multirow{2}{*}{ NS } \\
\hline & Post & 150.22 & 17.35 & & 167.81 & 27.55 & & 164.22 & 21.15 & & 156.82 & 27.03 & & 159.42 & 37.34 & \\
\hline
\end{tabular}


Table 3. Cont.

\begin{tabular}{|c|c|c|c|c|c|c|c|c|c|c|c|c|c|c|c|c|}
\hline & & \multicolumn{3}{|c|}{$<2$ Years } & \multicolumn{3}{|c|}{ 2-6 Years } & \multicolumn{3}{|c|}{ 7-10 Years } & \multicolumn{3}{|c|}{ 11-17 Years } & \multicolumn{3}{|c|}{$\geq 18$ Years } \\
\hline & & Mean & SD & $p$ & Mean & SD & $p$ & Mean & SD & $p$ & Mean & SD & $p$ & Mean & SD & $p$ \\
\hline \multirow{2}{*}{$\begin{array}{l}\text { Triglycerides } \\
\text { (mg/dL) }\end{array}$} & Pre & 73.56 & 17.07 & \multirow[b]{2}{*}{ NS } & 76.83 & 30.09 & \multirow[b]{2}{*}{0.047} & 62.39 & 20.74 & \multirow[b]{2}{*}{ NS } & 77.57 & 37.99 & \multirow[b]{2}{*}{0.050} & 88.19 & 54.66 & \multirow[b]{2}{*}{ NS } \\
\hline & Post & 67.89 & 20.76 & & 69.97 & 20.52 & & 66.42 & 25.62 & & 95.45 & 78.58 & & 84.85 & 44.61 & \\
\hline \multirow{2}{*}{$\begin{array}{c}\text { HDL } \\
(\mathrm{mg} / \mathrm{dL})\end{array}$} & Pre & 39.81 & 9.02 & \multirow{2}{*}{ NS } & 49.82 & 11.00 & \multirow{2}{*}{$<0.001$} & 58.23 & 15.12 & \multirow{2}{*}{0.008} & 53.14 & 11.11 & \multirow{2}{*}{ NS } & 52.05 & 14.24 & \multirow{2}{*}{ NS } \\
\hline & Post & 45.60 & 8.23 & & 55.38 & 9.62 & & 63.19 & 11.93 & & 53.07 & 11.77 & & 52.45 & 12.16 & \\
\hline \multirow{2}{*}{$\begin{array}{c}\text { LDL } \\
(\mathrm{mg} / \mathrm{dL})\end{array}$} & Pre & 84.78 & 25.92 & \multirow{2}{*}{ NS } & 98.80 & 26.99 & \multirow{2}{*}{ NS } & 87.25 & 20.54 & \multirow{2}{*}{ NS } & 88.00 & 23.97 & \multirow{2}{*}{ NS } & 90.96 & 31.75 & \multirow{2}{*}{ NS } \\
\hline & Post & 91.11 & 14.13 & & 98.58 & 25.90 & & 87.72 & 19.86 & & 87.05 & 23.75 & & 90.92 & 32.47 & \\
\hline \multirow{2}{*}{$\begin{array}{l}\text { Fasting glucose } \\
(\mathrm{mg} / \mathrm{dL})\end{array}$} & Pre & 82.33 & 3.24 & \multirow{2}{*}{ NS } & 81.44 & 9.48 & \multirow{2}{*}{ NS } & 88.00 & 7.43 & \multirow{2}{*}{ NS } & 90.44 & 7.56 & \multirow{2}{*}{ NS } & 88.81 & 7.12 & \multirow{2}{*}{ NS } \\
\hline & Post & 80.78 & 8.71 & & 85.63 & 12.44 & & 89.31 & 8.43 & & 91.76 & 7.90 & & 96.40 & 32.63 & \\
\hline \multirow{2}{*}{$\begin{array}{l}\text { OGTT } 30 \mathrm{~min} \\
(\mathrm{mg} / \mathrm{dL})\end{array}$} & Pre & 127.60 & 17.57 & \multirow{2}{*}{ NS } & 145.91 & 28.75 & & 152.47 & 31.19 & & 155.14 & 23.70 & & 149.21 & 30.37 & \\
\hline & Post & 134.20 & 33.25 & & 149.64 & 27.17 & NS & 165.14 & 28.53 & 0.035 & 158.11 & 26.80 & NS & 158.63 & 34.50 & NS \\
\hline OGTT $60 \mathrm{~min}$ & Pre & 112.60 & 28.84 & & 126.77 & 26.58 & & 133.61 & 19.87 & & 142.66 & 30.74 & & 139.92 & 42.93 & \\
\hline$(\mathrm{mg} / \mathrm{dL})$ & Post & 124.60 & 43.33 & NS & 129.88 & 31.62 & NS & 137.11 & 32.15 & NS & 148.82 & 36.65 & NS & 157.17 & 41.88 & 0.006 \\
\hline OGTT $120 \mathrm{~min}$ & Pre & 111.60 & 32.76 & & 105.61 & 17.67 & & 110.47 & 19.43 & & 114.76 & 22.14 & & 111.76 & 20.44 & \\
\hline$(\mathrm{mg} / \mathrm{dL})$ & Post & 109.60 & 21.42 & NS & 111.50 & 19.35 & 0.026 & 121.31 & 20.99 & 0.006 & 123.55 & 31.46 & NS & 121.67 & 32.13 & NS \\
\hline$(\mathrm{pU} / \mathrm{dL})$ & Post & 2.42 & 1.70 & NS & 4.24 & 3.05 & NS & 7.79 & 3.79 & 0.042 & 15.34 & 19.21 & NS & 5.12 & 1.76 & 0.003 \\
\hline Vitamin D & Pre & 92.75 & 66.40 & & 65.43 & 23.91 & & 74.44 & 48.48 & & 66.59 & 29.19 & & 75.50 & 23.99 & \\
\hline$(\mathrm{nmol} / \mathrm{L})$ & Post & 88.70 & 50.91 & NS & 80.04 & 22.33 & $<0.001$ & 75.44 & 22.55 & NS & 76.70 & 26.45 & 0.004 & 97.79 & 21.93 & 0.001 \\
\hline
\end{tabular}

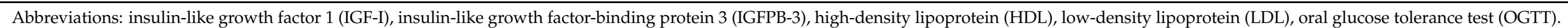




\subsection{Growth Hormone Therapy and the Development of Weight/BMI/LBM}

Most children (90.2\%) and two adults (7\%) received GH during the lockdown (Table 1). The dosage did not change significantly during the observational period (pre-lockdown mean: $0.0261 \mathrm{mg} / \mathrm{kg}$ vs. intra-lockdown mean: $0.0257 \mathrm{mg} / \mathrm{kg}, p=0.225)$. The correlation between dosage change $(\mathrm{mg} / \mathrm{kg})$ and the change in IGF-I concentration did not reach statistical significance $(p=0.697)$. Assessing the entire cohort above the age of two, we found significant correlations between the GH intra-lockdown dosage $(\mathrm{mg} / \mathrm{kg})$ and the development of weight $(\mathrm{kg})(\mathrm{r}=-0.286, p=0.001$; Figure 1$)$, weight-SDS $\mathrm{PWS}_{\mathrm{PW}}(\mathrm{r}=-0.183, p=0.037)$, and BMI-SDS PWS $(\mathrm{r}=-0.189, p=0.031$; Figure 2). The correlation between GH dosage and LBM development was non-significant $(\mathrm{r}=-0.107, p=0.274)$. Calculated for the different age groups, correlations between GH dosage and weight-SDS PwS $_{\text {BMI-SDS }}$ PwS only remained significant in the 2-6-year-olds (weight-SDS PWs $\mathrm{r}=-0.344, p=0.010$; BMI-SDS PWS $_{\text {: }}$ $\mathrm{r}=-0.365, p=0.006)$.

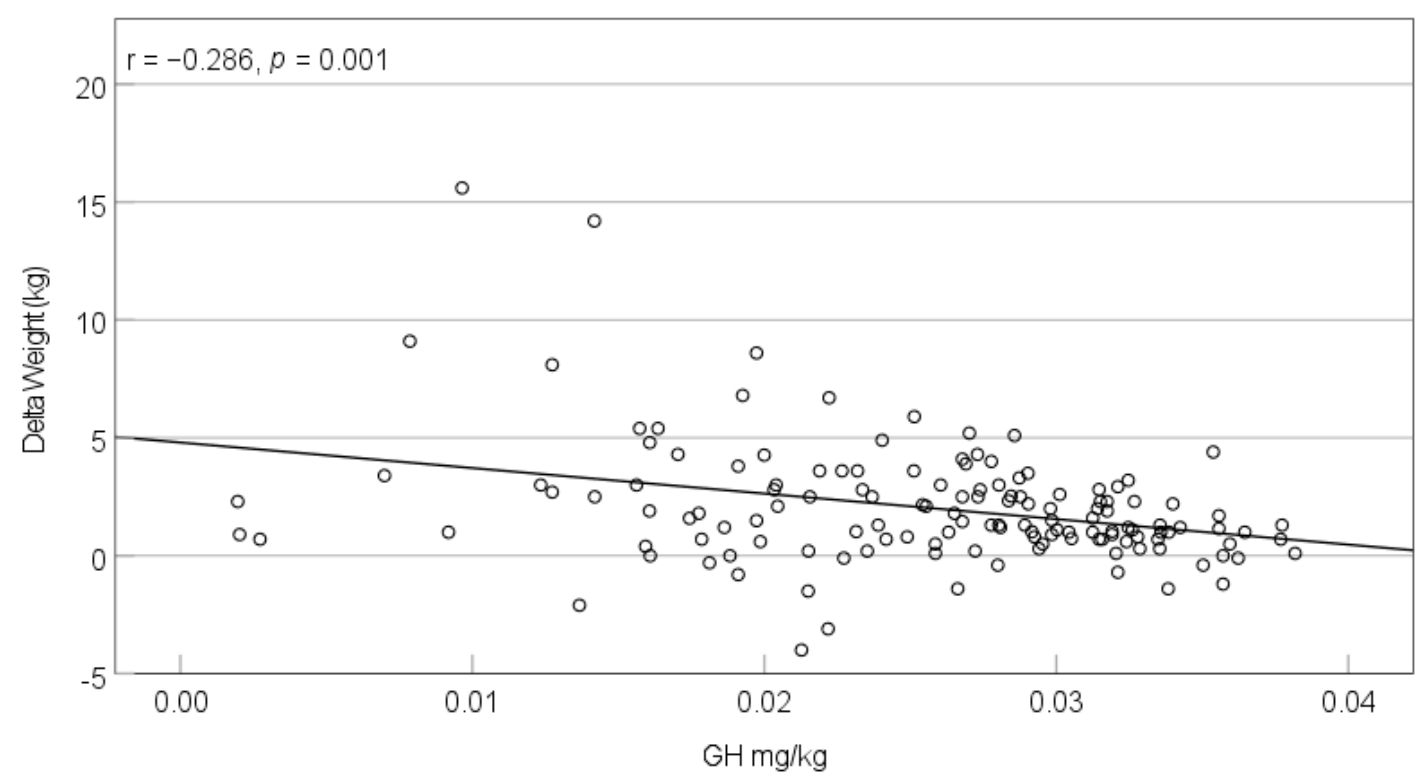

Figure 1. Correlation between the intra-lockdown $\mathrm{GH}$ dosage $(\mathrm{mg} / \mathrm{kg})$ and weight change $(\mathrm{kg})$ during the lockdown period in March-April 2020 in individuals with PWS >2 years.

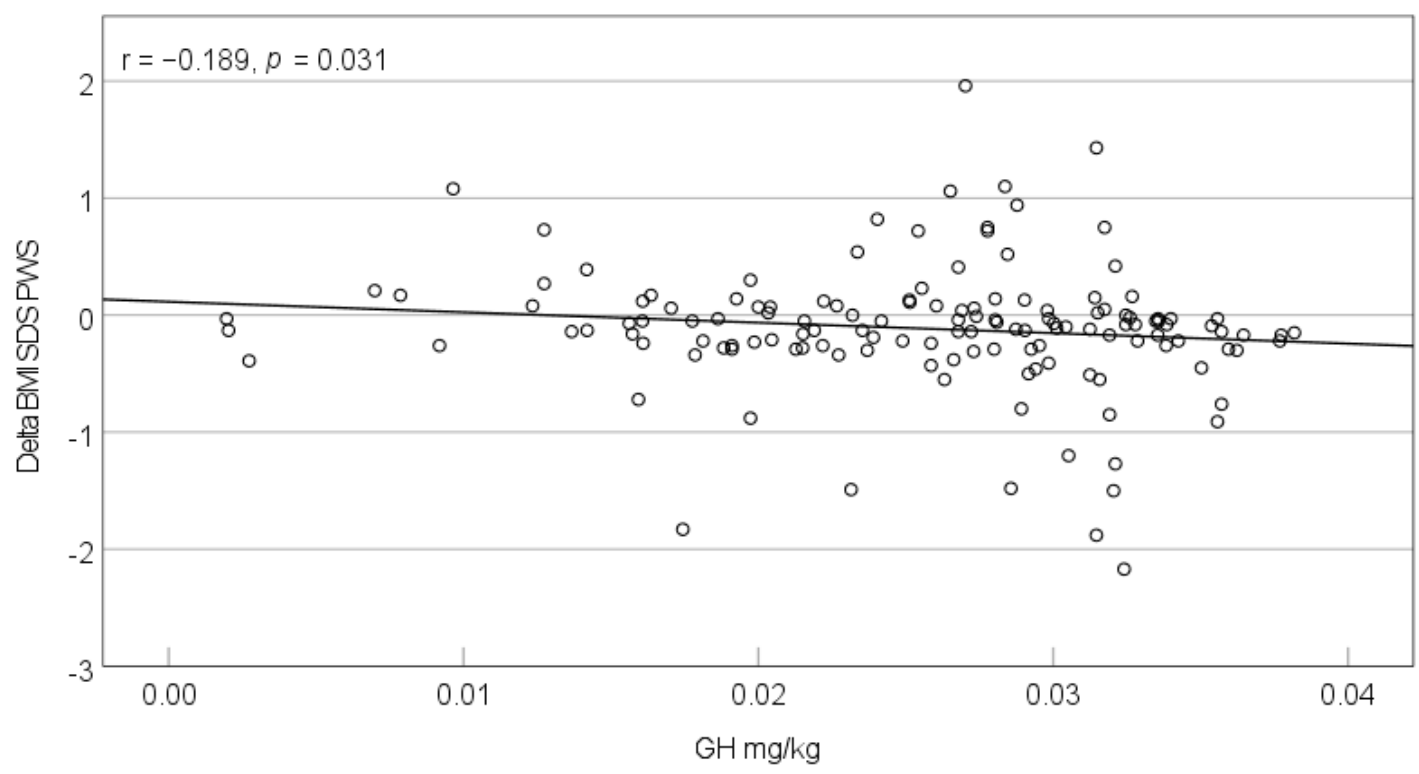

Figure 2. Correlation between the intra-lockdown GH dosage $(\mathrm{mg} / \mathrm{kg}$ ) and change in BMI-SDSPWS during the lockdown period in March-April 2020 in individuals with PWS >2 years. 


\subsection{The Questionnaire}

All participants completed the questionnaire. None of the individuals with PWS suffered from a COVID-19 infection. Forty-two children and adolescents $(23.8 \%)$ contracted another illness (in $92.9 \%$, an upper respiratory tract infection, gastroenteritis, or ear-nosethroat condition), five children $(2.8 \%)$ had a scheduled surgery, and $22(12.4 \%)$ received a new medication (in 95.5\%, a non-steroidal anti-inflammatory drug, antibiotic, antipsychotic, or inhalative agent). One family lost a family member due to a COVID-19 infection.

\subsubsection{Living Environment}

Most families lived in a rural living environment defined as $<20,000$ inhabitants $(56.6 \%)$ and owned a house $(74.1 \%)$ with a garden $(73.1 \%)$. A total of $16 \%$ of children with PWS were a single child. About half of the families (52.7\%) experienced a change in their daily routine during the lockdown. Most families reported keeping set mealtimes $(95.4 \%)$ and activities $(72.2 \%)$. Overall, $47.2 \%$ reported family life during the lockdown as strenuous, $33.1 \%$ as very strenuous. The highest percentage of parents not describing the family situation as strenuous was found in the $<2$-year-olds with $37.5 \%$, followed by the 2-6-year-olds with $22.6 \%$. The highest percentages of parents rating family life as very strenuous were seen in the 11-17-year-olds (50\%) and 7-10-year-olds (36.1\%). Regarding occupational changes, 67 fathers $(42.4 \%)$ and 63 mothers (45.7\%) reported a change caused by the pandemic. A total of 39 fathers $(27 \%)$ and 36 mothers (29.5\%) were sent to work from home or for short-time work during the lockdown.

\subsubsection{Care and Therapies during COVID-19 Lockdown}

Most families (88.7\%) reported a discontinuation of childcare services. Care facilities were closed between 1 and 25 weeks, with a median duration of 12 weeks. Every fifth individual with PWS (21.2\%) received a form of emergency care, which reached prelockdown capacity in $21.4 \%$. Regarding the different age groups, a break in childcare services occurred most frequently in the 7-10-year-olds (100\%), 11-17-year-olds (95.5\%), and 2-6-year-olds (93.3\%). In the young adults, about half (54.2\%) experienced a closure of care facilities. As 9 out of $10<2$-year-olds had been cared for at home previous to the lockdown, only one family reported a discontinuation of childcare services. At the time of completing the questionnaire, $56.7 \%$ of all families reported a restart of care services, reaching the pre-lockdown extent in $48.1 \%$. Therapy sessions were canceled in most cases $(86 \%)$, of which $17.1 \%$ were offered support by their therapists via video conferencing sessions, training schedules, video instructions, or phone calls.

\subsubsection{Behavior Changes during COVID-19 Lockdown}

Median behavioral ratings for the lockdown period were " 0 " for children $<2$ years, "2" for 2-6-year-olds, " 4 " for 7-10-year-olds, " 5 " for adolescents aged 11-17 years, and " 3 " for young adults $\geq 18$ years of age. Overall, 81 parents and caregivers $(45.7 \%)$ described an increase in behavioral problems during the lockdown; an improvement was reported in 22 cases $(12.4 \%)$. Comparing the behavior pre- and post-lockdown, 89 parents and caregivers did not experience a behavioral change (55.6\%), 54 reported a persistent increase in behavioral problems (33.7\%), and 17 a decrease (10.6\%). Regarding the different age groups, parental behavior ratings significantly increased from pre- to intra-lockdown in all children and adolescents above the age of 2. Comparing intra- and post-lockdown behavior, parental ratings decreased significantly in children aged 2-6 years and young adults. In the groups of the 7-10- and 11-17-year-olds, no significant changes in parental ratings comparing intra- and post-lockdown behavior were found. Data of the different age groups are presented in Table 4. 
Table 4. Behavioral problems reported by parents.

\begin{tabular}{|c|c|c|c|c|c|c|c|c|c|c|c|c|c|c|c|c|c|c|c|c|}
\hline & \multicolumn{4}{|c|}{$<2$ Years } & \multicolumn{4}{|c|}{ 2-6 Years } & \multicolumn{4}{|c|}{ 7-10 Years } & \multicolumn{4}{|c|}{ 11-17 Years } & \multicolumn{4}{|c|}{$\geq 18$ Years } \\
\hline & Less & Equal & More & $p$ & Less & Equal & More & $p$ & Less & Equal & More & $p$ & Less & Equal & More & $p$ & Less & Equal & More & $p$ \\
\hline $\begin{array}{l}\text { Intra-pre- } \\
\text { lockdown }\end{array}$ & 2 & 6 & 0 & 0.500 & 3 & 35 & 20 & 0.000 & 6 & 12 & 20 & 0.011 & 6 & 13 & 27 & 0.000 & 5 & 8 & 14 & 0.064 \\
\hline $\begin{array}{l}\text { Post-intra- } \\
\text { lockdown }\end{array}$ & 0 & 7 & 0 & 1.000 & 12 & 36 & 3 & 0.035 & 13 & 13 & 8 & 0.383 & 15 & 21 & 8 & 0.210 & 12 & 10 & 2 & 0.013 \\
\hline $\begin{array}{l}\text { Post-pre- } \\
\text { lockdown }\end{array}$ & 2 & 5 & 0 & 0.500 & 3 & 41 & 7 & 0.344 & 2 & 16 & 16 & 0.001 & 6 & 18 & 20 & 0.011 & 4 & 9 & 11 & 0.118 \\
\hline
\end{tabular}

Bahvioral problems reported by parents for each participant with PWS comparing intra- vs. pre-, post- vs. intra-, and post- vs. pre-lockdown behavior. Behavioral problems were rated on a 0 to 9 Likert scale, " 0 " meaning no behavioral problems, " 9 " severe behavioral problems.

\subsection{Multiple Regression Analysis}

The multiple regression analysis did not show a strong association between one factor and post-lockdown outcomes.

\section{Discussion}

The purpose of this study was the assessment of the impact of the lockdown in March and April 2020 on children, adolescents, and young adults with PWS. Among the most important findings of this study were the changes seen in anthropometric parameters, especially regarding the development of weight/BMI and lean mass. Previous studies have shown weight gain among healthy children during times of school closure due to loss of structured physical exercise and an increase in free time commonly used for sedentary activities [17-19]. Studies conducted during the COVID-19 pandemic found that children were less active and more sedentary; therefore, concern about weight gain among children has been expressed [20-23]. As weight gain is part of the natural history of PWS, we hypothesized that weight and BMI would increase in children, adolescents, and young adults with PWS. Interestingly, our study showed contrary results: both weight-SDS PWS

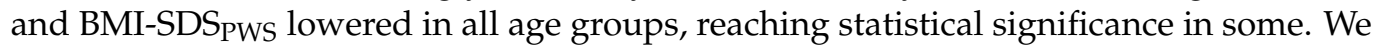
observed a significant decrease in weight-SDS PWS $_{\text {in children aged 7-10 years, BMI-SDS }}$ PWS decreased significantly in the $<2$ - and 7-10-year-olds. Similarly, in adults, weight and BMI decreased, however, non-significantly. Even though weight and BMI did not decrease in some age groups, maintaining a stable weight and BMI is considered the opposite of the natural history of PWS and can be seen as a favorable outcome [3,10].

Regarding body composition, we found a statistically significant increase in lean mass in all children and adolescents. An increase in LBM could have been caused by increased total body water, which was only assessed in the minority of participants. However, none of the participants was reported to have cardiac failure, and only one suffered from beginning renal failure, making a gain in muscle mass more likely than water retention.

There are various factors, which might explain the positive development of a stable weight/BMI and even improved body composition. First, we observed an increase in serum IGF-I and IGFBP-3 concentrations. Individuals with PWS show symptoms of GH deficiency, such as low IGF-I concentrations and abnormal body composition. Muscle mass is reduced, and fat mass increased, even in individuals with PWS with a normal BMI [7,10]. Therapy with GH increases IGF-I and IGFBP-3 concentrations and has been shown to have various benefits, including improvement of body composition and BMI [7,10]. In our cohort, $77.7 \%$ of all and $90.2 \%$ of individuals below the age of 18 received GH therapy during the lockdown. In most participants, the intra-lockdown GH dosage was determined at the pre-lockdown assessment in the clinic. When families were unable to attend the clinic, appointments were held over the phone. In these cases, GH dosages were adjusted based on laboratory tests performed by family physicians. An increase in prescribed GH dosage over the lockdown period could have explained the increased IGF-I and IGFBP3 concentrations. However, as there was no difference in dosage adjusted to body weight received before and during the lockdown, and the correlation between changes in $\mathrm{GH}$ dosage and IGF-I concentrations was non-significant, a plausible alternative explanation for 
the increased concentrations might be an increase in therapy adherence. We did not directly assess therapy adherence, but it has previously been described to be suboptimal in pediatric populations [24]. An increase in GH therapy adherence during the COVID-19 pandemic was reported by Giavoli et al., indicating that home confinement influenced the adherence rate positively [25]. We therefore speculate that the individuals with PWS received a more continuous GH administration due to more flexible family routines and fewer travels during the lockdown. As mentioned, GH therapy is associated with improvements in body composition, including improvements in lean mass. However, we could not find a significant correlation between the dosage of intra-lockdown GH therapy and the observed positive change in LBM. This might be due to the little variation in GH dosage for the group. Only a small percentage of the population did not receive GH treatment; therefore, a comparison of the change in LBM during the lockdown between the non-treatment group versus the treatment group was not possible. Regarding the effect of GH on total body weight and BMI of the entire cohort, we found significant correlations between the intra-lockdown GH dosage and change of weight-SDS PWS $_{\text {and BMI-SDS }}$ PWs. Higher dosages were associated with a reduction in weight and BMI. Calculated for the different age groups, these associations remained significant in children aged 2-6 years. Reasons for the statistically significant results in this age group might be the natural history of PWS, with a switch from failure to thrive to weight gain in this age range, higher therapy adherence in children than adolescents, or a larger sample size compared to the other groups [25].

Another common hormone deficiency in PWS is hypogonadism, and many adolescents and young adults receive sex steroid replacement therapy $[7,26]$. Apart from induction and progression of puberty, the benefits of sex steroid replacement, specifically testosterone replacement, include improvements in muscle mass and body composition. Individuals of two age groups received sex steroids: adolescents between 11 and 17 years of age and young adults $\geq 18$ years. However, in the 11-17-year-olds, only a minority received testosterone, as parents are commonly hesitant towards testosterone treatment, fearing an increase in behavioral problems. Moreover, in all adolescent boys, serum testosterone concentrations did not differ significantly pre- and post-lockdown. In the young adults, a majority took sex steroids, but no significant changes in weight and body composition were found. Therefore, we assume that sex steroid replacement therapy did not significantly impact the development of weight and lean mass in either age group.

As a second factor possibly influencing weight and body composition, we identified physical activity. Physical activity is a recommended treatment component, as it improves physical capacity and aids obesity management $[11,27]$. Regarding body composition, the impact of physical activity on LBM in individuals with PWS is ambiguous [28-30]. We did not directly assess the level of physical activity in our participants, but families reported keeping routines during the lockdown, and elevated vitamin D levels in the post-lockdown assessment indicate that families spent time outdoors. Keeping routines and being physically active, when possible outside, have been recommended to maintain healthy movement behaviors during the COVID-19 pandemic [31,32]. Supportive of the theory that enhanced physical activity impacted weight management, our regression analysis showed negative associations between set activities and changes of BMI-SDS $S_{\text {PWS }}$ and weight-SDS PWS $_{\text {, meaning that the presence of set activities caused lower BMI-SDS }}$ PWS and weight-SDS Pws. However, these associations only had a weak and weak-moderate effect, respectively.

A third possible factor was changes in eating behavior. As most families spent their days together at home, parents had greater control over the food consumed by their children, and almost all families (95.4\%) reported having structured mealtimes, a recommended obesity management strategy in PWS [11]. Continuous caregiver supervision was described to have created a favorable environment for adults with PWS by Mosbah et al., causing weight loss in $49 \%$ of French adults with PWS during the lockdown period [33]. Regarding metabolic changes, we observed an increase in HDL and a reduced 
triglyceride/HDL ratio in children. Together with the anthropometric results, this may reflect a more balanced diet and regular physical activity over the lockdown period [34,35]. However, improved lipid profiles have also been linked to GH therapy [36,37]. The slightly worsened blood glucose and insulin concentrations observed in some age groups might have been caused by the diabetogenic effects of the suspected GH increase [38].

We, therefore, suggest that the favorable development seen in weight/BMI and body composition results from an interplay of the suspected enhanced GH therapy and parental commitment. As discussed above, GH therapy improves body composition and physical capacity. However, the changes in LBM in our population cannot solely be explained by GH treatment. Parental encouragement possibly led to increased physical activity and greater control over the food consumed, both recommended in the management of genetic obesity during the pandemic, also impacting weight/BMI and LBM [39]. Our multiple regression analyses further support the theory of a multifactorial process. To identify variables possibly impacting post-lockdown outcomes, we performed multiple regression analyses, including variables possibly affecting the development of weight and body composition. We differentiated between genetic subtypes, sex, post-lockdown age, and GH dosage, and included information given in the questionnaire, such as variables impacting physical activity (access to a garden, owning a dog, presence of set activities, living situation, and rural vs. urban neighborhood), eating behavior (presence of set mealtimes), or care and therapy received during the lockdown period. None of these variables showed a strong association with post-lockdown outcomes, showing that no single factor alone can be attributed to the observed changes.

We believe that these results might be reassuring to parents and caregivers of individuals with PWS, showing that the break of childcare services and therapies did not worsen weight and body composition. However, the results greatly depended on parental and caregiver commitment as external support was scarce during the lockdown, putting a significant burden on the families.

PWS negatively impacts the quality of life of individuals with PWS and their parents even under non-pandemic circumstances [40]. During the pandemic, Wieting et al. reported an increase in temper outbursts in $51.7 \%$ and increased irritability in $55 \%$ of individuals with PWS [41]. In our population, $45.7 \%$ of parents and caregivers reported more intense behavioral problems during the lockdown period, and family life was described as strenuous/very strenuous in $80.3 \%$. Regarding the different age groups, significant increases in behavioral problems were reported in all children and adolescents above the age of 2. In young adults, a non-significant trend towards an increase in behavioral problems was noted. In children aged 2-6 years and young adults, parental ratings decreased significantly post-lockdown, but not in children and adolescents aged 7-10 and 11-17 years. Instead, significant differences between pre- and post-lockdown behavior were reported in these two groups, showing that the intensified behavioral problems persisted into the post-lockdown period. Moreover, median behavioral ratings were highest in these two age groups; therefore, it is not surprising that the percentages of parents/caregivers describing family life as very strenuous were highest in these groups. Mental and behavioral problems, as well as caregiver burden, have been described to be highest in adolescents, even under non-pandemic circumstances [42]. Additionally, as the closure rates of care services in these groups were highest, it is likely that children and adolescents in the 7-10- and 11-17-year-old groups and their families suffered most during the COVID-19 lockdown.

Overall, with more intense behavioral problems persisting after the first lockdown in March-April 2020 in one-third of all participants, the families' burden continued into the post-lockdown period and was potentially further worsened by following lockdowns during the ongoing pandemic.

\section{Strengths and Limitations}

An increasing amount of research is being conducted assessing the mental and physical consequences of the COVID-19 pandemic on children. To the best of our knowledge, this is 
the first study evaluating the impact of the lockdown on weight and body composition of children, adolescents, and young adults with PWS. A strength of this single-center study is the evaluation of a large study cohort. In total, 231 individuals with PWS visited the clinic throughout 2020, of which we included $77.9 \%$ in our study, making the cohort representative for the population seen in our clinic. One important limitation is the two examinations not occurring right before and after the lockdown. Moreover, we did not use a standardized follow-up, nor questionnaire, and many study results rely on retrospective self-reporting. Furthermore, we did not assess therapy adherence. Due to missing memory functions in GH preparations licensed for use in PWS in Germany, an objective assessment of therapy adherence was not possible. Next, a pubertal growth spurt in the 11-17-yearolds could have impacted the development of height, weight, and BMI. It must also be noted that more than $70 \%$ of our population lived in a house with access to a garden. Therefore, our results might not be transferrable to populations living under less privileged conditions. Moreover, total body water was only assessed in the minority of participants. We can only assume that the increase in LBM was caused by an increase in muscle mass rather than water retention. In future research, complete body composition analyses should be performed in all participants. Further, due to the low percentage of individuals not receiving GH therapy, no statistical analysis investigating these children and adolescents separately was performed. Therefore, we could not identify the separate impacts of GH therapy and lifestyle variables on post-lockdown outcomes.

\section{Conclusions}

This study assessed the impact of the first COVID-19 lockdown on children, adolescents, and young adults with PWS living in Germany, showing a favorable development of weight/BMI and LBM. We suggest that these outcomes were caused by an interplay of enhanced GH administration and continuous parental supervision. Caring for their children with PWS without or only minimal support put a significant burden on the families. Enhanced behavioral problems were observed in almost half of the individuals with PWS, which persisted in one-third into the post-lockdown period. Our results highlight the beneficial effects of a multifactorial therapy comprising GH treatment, physical activity, and diet control. However, the results also stress the importance of multidisciplinary care to mitigate the burden on individuals with PWS and their families.

Supplementary Materials: The following are available online at https://www.mdpi.com/article/10 .3390/jcm10204746/s1, S1: The Questionnaire.

Author Contributions: Conceptualization, B.G. and C.L.; methodology, B.G. and C.L.; formal analysis, S.S. and A.K.M.; investigation, A.K.M.; resources, C.L.; data curation, S.S.; writing—original draft preparation, A.K.M.; writing—review and editing, B.G., C.L. and S.S.; visualization, A.K.M.; supervision, B.G., C.L. and S.S.; project administration, B.G.; funding acquisition, B.G. All authors have read and agreed to the published version of the manuscript.

Funding: This research was funded by Pfizer ${ }^{\circledR}$, grant number CUNO 20000926.

Institutional Review Board Statement: The study was conducted according to the guidelines of the Declaration of Helsinki, and approved by the Ethics Committee of the University of Bonn (31/15; Amendment 06/20).

Informed Consent Statement: Informed consent was obtained from all subjects involved in the study.

Data Availability Statement: The datasets generated during this study are not publicly available in order to protect the privacy of the patients who participated in this study.

Conflicts of Interest: The authors declare no conflict of interest. 


\section{References}

1. Butler, M.G.; Miller, J.L.; Forster, J.L. Prader-Willi Syndrome-Clinical Genetics, Diagnosis and Treatment Approaches: An Update. Curr. Pediatr. Rev. 2019, 15, 207-244. [CrossRef] [PubMed]

2. Cassidy, S.B.; Schwartz, S.; Miller, J.L.; Driscoll, D.J. Prader-Willi syndrome. Genet. Med. 2012, 14, 10-26. [CrossRef] [PubMed]

3. Crinò, A.; Fintini, D.; Bocchini, S.; Grugni, G. Obesity management in Prader-Willi syndrome: Current perspectives. Diabetes Metab. Syndr. Obes. 2018, 11, 579-593. [CrossRef] [PubMed]

4. Coupaye, M.; Tauber, M.; Cuisset, L.; Laurier, V.; Bieth, E.; Lacorte, J.M.; Oppert, J.M.; Clément, K.; Poitou, C. Effect of Genotype and Previous GH Treatment on Adiposity in Adults With Prader-Willi Syndrome. J. Clin. Endocrinol. Metab. 2016, 101, 4895-5903. [CrossRef] [PubMed]

5. $\quad$ Reus, L.; Zwarts, M.; van Vlimmeren, L.A.; Willemsen, M.A.; Otten, B.J.; van der Sanden, M.W.N. Motor problems in Prader-Willi syndrome: A systematic review on body composition and neuromuscular functioning. Neurosci. Biobehav. Rev. 2011, 35, 956-969. [CrossRef]

6. Heksch, R.; Kamboj, M.; Anglin, K.; Obrynba, K. Review of Prader-Willi syndrome: The endocrine approach. Transl. Pediatr. 2017, 6, 274-285. [CrossRef]

7. Emerick, J.E.; Vogt, K.S. Endocrine manifestations and management of Prader-Willi syndrome. Int. J. Pediatr. Endocrinol. 2013, 2013, 14. [CrossRef]

8. Butler, M.G. Prader-Willi Syndrome: Obesity due to Genomic Imprinting. Curr. Genom. 2011, 12, 204-215. [CrossRef]

9. Butler, M.G.; Theodoro, M.F.; Bittel, D.C.; Donnelly, J.E. Energy expenditure and physical activity in Prader-Willi syndrome: Comparison with obese subjects. Am. J. Med. Genet. A 2007, 143A, 449-459. [CrossRef]

10. Passone, C.G.B.; Franco, R.R.; Ito, S.S.; Trindade, E.; Polak, M.; Damiani, D.; Bernardo, W.M. Growth hormone treatment in Prader-Willi syndrome patients: Systematic review and meta-analysis. BMJ Paediatr. Open 2020, 4, e000630. [CrossRef]

11. Goldstone, A.; Holland, A.J.; Hauffa, B.P.; Hokken-Koelega, A.C.; Tauber, M. Recommendations for the Diagnosis and Management of Prader-Willi Syndrome. J. Clin. Endocrinol. Metab. 2008, 93, 4183-4197. [CrossRef] [PubMed]

12. Cucinotta, D.; Vanelli, M. WHO Declares COVID-19 a Pandemic. Acta Biomed. 2020, 91, 157-160. [PubMed]

13. Bedford, J.; Enria, D.; Giesecke, J.; Heymann, D.L.; Ihekweazu, C.; Kobinger, G.; Lane, H.C.; Memish, Z.; Oh, M.D.; Sall, A.A.; et al. COVID-19: Towards controlling of a pandemic. Lancet 2020, 395, 1015-1018. [CrossRef]

14. Sharma, A.; Metzger, D.L. Calculator: Prader-Willi Syndrome Z-Scores 0-18y. Available online: https://apps.cpeg-gcep.net/ PWSZ_cpeg/ (accessed on 4 November 2020).

15. Völgyi, E.; Tylavsky, F.A.; Lyytikäinen, A.; Suominen, H.; Alén, M.; Cheng, S. Assessing body composition with DXA and bioimpedance: Effects of obesity, physical activity, and age. Obesity 2008, 16, 700-705. [CrossRef] [PubMed]

16. Kyle, U.G.; Bosaeus, I.; De Lorenzo, A.D.; Deurenberg, P.; Elia, M.; Gómez, J.M.; Heitmann, B.L.; Kent-Smith, L.; Melchior, J.C.; Pirlich, M.; et al. Bioelectrical impedance analysis-part I: Review of principles and methods. Clin. Nutr. 2004, 23, 1226-1243. [CrossRef]

17. Franckle, R.; Adler, R.; Davison, K. Accelerated Weight Gain Among Children During Summer Versus School Year and Related Racial/Ethnic Disparities: A Systematic Review. Prev. Chronic Dis. 2014, 11, E101. [CrossRef]

18. Weaver, R.G.; Beets, M.W.; Brazendale, K.; Brusseau, T.A. Summer Weight Gain and Fitness Loss: Causes and Potential Solutions. Am. J. Lifestyle Med. 2018, 13, 116-128. [CrossRef]

19. Brazendale, K.; Beets, M.W.; Weaver, R.G.; Pate, R.R.; Turner-McGrievy, G.M.; Kaczynski, A.T.; Chandler, J.L.; Bohnert, A.; Von Hippel, P.T. Understanding differences between summer vs. school obesogenic behaviors of children: The structured days hypothesis. Int. J. Behav. Nutr. Phys. Act. 2017, 14, 1-14. [CrossRef]

20. Dunton, G.F.; Do, B.; Wang, S.D. Early effects of the COVID-19 pandemic on physical activity and sedentary behavior in children living in the U.S. BMC Public Health 2020, 20, 1351.

21. Pietrobelli, A.; Pecoraro, L.; Ferruzzi, A.; Heo, M.; Faith, M.; Zoller, T.; Antoniazzi, F.; Piacentini, G.; Fearnbach, S.N.; Heymsfield, S.B. Effects of COVID-19 Lockdown on Lifestyle Behaviors in Children with Obesity Living in Verona, Italy: A Longitudinal Study. Obesity 2020, 28, 1382-1385. [CrossRef]

22. Rundle, A.G.; Park, Y.; Herbstman, J.B.; Kinsey, E.W.; Wang, Y.C. COVID-19-Related School Closings and Risk of Weight Gain Among Children. Obesity 2020, 28, 1008-1009. [CrossRef] [PubMed]

23. The Lancet Child \& Adolescent Health. Pandemic school closures: Risks and opportunities. Lancet Child Adolesc. Health 2020, 4, 341. [CrossRef]

24. Fisher, B.G.; Acerini, C.L. Understanding the growth hormone therapy adherence paradigm: A systematic review. Horm. Res. Paediatr. 2013, 79, 189-196. [CrossRef] [PubMed]

25. Giavoli, C.; Profka, E.; Giancola, N.; Rodari, G.; Giacchetti, F.; Ferrante, E.; Arosio, M.; Mantovani, G. Growth hormone therapy at the time of Covid-19 pandemic: Adherence and drug supply issues. Eur. J. Endocrinol. 2020, 183, L13-L15. [CrossRef] [PubMed]

26. Napolitano, L.; Barone, B.; Morra, S.; Celentano, G.; Rocca, R.L.; Capece, M.; Morgera, V.; Turco, C.; Caputo, V.F.; Spena, G.; et al. Hypogonadism in Patients with Prader Willi Syndrome: A Narrative Review. Int. J. Mol. Sci. 2021, 22, 1993. [CrossRef]

27. Morales, J.S.; Valenzuela, P.L.; Pareja-Galeano, H.; Rincón-Castanedo, C.; Rubin, D.A.; Lucia, A. Physical exercise and Prader-Willi syndrome: A systematic review. Clin. Endocrinol. 2019, 90, 649-661. [CrossRef]

28. Eiholzer, U.; Nordmann, Y.; l'Allemand, D.; Schlumpf, M.; Schmid, S.; Kromeyer-Hauschild, K. Improving body composition and physical activity in Prader-Willi Syndrome. J. Pediatr. 2003, 142, 73-78. [CrossRef] 
29. Rubin, D.A.; Duran, A.; Haqq, A.M.; Gertz, E.R.; Dumont-Driscoll, M. Changes in cardiometabolic markers in children with Prader-Willi syndrome and nonsyndromic obesity following participation in a home-based physical activity intervention. Pediatr. Obes. 2018, 13, 734-743. [CrossRef]

30. Rubin, D.A.; Wilson, K.S.; Castner, D.M.; Dumont-Driscoll, M.C. Changes in Health-Related Outcomes in Youth With Obesity in Response to a Home-Based Parent-Led Physical Activity Program. J. Adolesc. Health 2019, 65, 323-330. [CrossRef]

31. Moore, S.A.; Faulkner, G.; Rhodes, R.E.; Brussoni, M.; Chulak-Bozzer, T.; Ferguson, L.J.; Mitra, R.; O’Reilly, N.; Spence, J.C.; Vanderloo, L.M.; et al. Impact of the COVID-19 virus outbreak on movement and play behaviours of Canadian children and youth: A national survey. Int. J. Behav. Nutr. Phys. Act. 2020, 17, 1-11. [CrossRef]

32. Guan, H.; Okely, A.D.; Aguilar-Farias, N.; Cruz, B.D.P.; Draper, C.E.; El Hamdouchi, A.; Florindo, A.A.; Jáuregui, A.; Katzmarzyk, P.T.; Kontsevaya, A.; et al. Promoting healthy movement behaviours among children during the COVID-19 pandemic. Lancet Child Adolesc. Health 2020, 4, 416-418. [CrossRef]

33. Mosbah, H.; Coupaye, M.; Jacques, F.; Tauber, M.; Clément, K.; Oppert, J.-M.; Poitou, C. Effects of the COVID-19 pandemic and lockdown on the mental and physical health of adults with Prader-Willi syndrome. Orphanet J. Rare Dis. 2021, 16, 1-6. [CrossRef] [PubMed]

34. Irizarry, K.A.; Mager, D.R.; Triador, L.; Muehlbauer, M.J.; Haqq, A.M.; Freemark, M. Hormonal and metabolic effects of carbohydrate restriction in children with Prader-Willi syndrome. Clin. Endocrinol. 2019, 90, 553-561. [CrossRef] [PubMed]

35. Bedogni, G.; Grugni, G.; Cicolini, S.; Caroli, D.; Tamini, S.; Sartorio, A. Changes of Body Weight and Body Composition in Obese Patients with Prader-Willi Syndrome at 3 and 6 Years of Follow-Up: A Retrospective Cohort Study. J. Clin. Med. 2020, 9, 3596. [CrossRef] [PubMed]

36. Carrel, A.L.; Myers, S.E.; Whitman, B.Y.; Allen, D.B. Growth hormone improves body composition, fat utilization, physical strength and agility, and growth in Prader-Willi syndrome: A controlled study. J. Pediatr. 1999, 134, 215-221. [CrossRef]

37. l'Allemand, D.; Eiholzer, U.; Schlumpf, M.; Steinert, H.; Riesen, W. Cardiovascular risk factors improve during 3 years of growth hormone therapy in Prader-Willi syndrome. Eur. J. Pediatr. 2000, 159, 835-842. [CrossRef]

38. Kim, S.-H.; Park, M.-J. Effects of growth hormone on glucose metabolism and insulin resistance in human. Ann. Pediatr. Endocrinol. Metab. 2017, 22, 145-152. [CrossRef] [PubMed]

39. De Groot, C.J.; Bernert, C.P.; Coupaye, M.; Clement, K.; Paschou, S.A.; Charmandari, E.; Kanaka-Gantenbein, C.; Wabitsch, M.; Buddingh, E.P.; Nieuwenhuijsen, B.; et al. Clinical management of patients with genetic obesity during COVID-19 pandemic: Position paper of the ESE Growth \& Genetic Obesity COVID-19 Study Group and Rare Endo-ERN main thematic group on Growth and Obesity. Endocrine 2021, 71, 653-662.

40. Meade, C.; Martin, R.; McCrann, A.; Lyons, J.; Meehan, J.; Hoey, H.; Roche, E. Prader-Willi Syndrome in children: Quality of life and caregiver burden. Acta Paediatr. 2020, 110, 1665-1670. [CrossRef]

41. Wieting, J.; Eberlein, C.; Bleich, S.; Frieling, H.; Deest, M. Behavioural change in Prader-Willi syndrome during COVID19 pandemic. J. Intellect. Disabil. Res. 2021, 65, 609-616. [CrossRef]

42. Feighan, S.-M.; Hughes, M.; Maunder, K.; Roche, E.; Gallagher, L. A profile of mental health and behaviour in Prader-Willi syndrome. J. Intellect. Disabil. Res. 2019, 64, 158-169. [CrossRef] 